\title{
Changes in patterns of extracorporeal cardiopulmonary resuscitation during the COVID-19 pandemic
}

\author{
Pauline Yeung $\mathrm{Ng}^{1,2 \#} \wedge$, Shu Fang ${ }^{1 \#}$, April $\mathrm{Ip}^{1}$, Andrew Kei-Yan $\mathrm{Ng}^{3}$, Wai Ming Chan ${ }^{2}$, Wai Ching Sin ${ }^{2,4}$, \\ Chun Wai Ngai ${ }^{2}$ \\ ${ }^{1}$ Department of Medicine, The University of Hong Kong, Hong Kong, China; ${ }^{2}$ Department of Adult Intensive Care, Queen Mary Hospital, Hong \\ Kong, China; ${ }^{3}$ Cardiac Medical Unit, Grantham Hospital, Hong Kong, China; ${ }^{4}$ Department of Anesthesiology, The University of Hong Kong, \\ Hong Kong, China \\ "These authors contributed equally to this work. \\ Correspondence to: Pauline Yeung Ng, MBBS, FHKCP. Department of Adult Intensive Care, Queen Mary Hospital, Room 345, Block L, Hong Kong, \\ China. Email: pyeungng@hku.hk.
}

Submitted Aug 31, 2021. Accepted for publication Oct 19, 2021.

doi: $10.21037 /$ jtd-21-1434

View this article at: https://dx.doi.org/10.21037/jtd-21-1434

During the COVID-19 pandemic, healthcare systems have reorganized services to accommodate the demands of COVID-19 surges, deprioritized resource-intensive services, and incorporated infection control requirements (1). Extracorporeal cardiopulmonary resuscitation (ECPR) refers to the use of extracorporeal membrane oxygenation (ECMO) during the process of cardiopulmonary resuscitation (CPR), and although was shown to be efficacious in randomized trials (2), remains an extremely complex adjunct in acute medical care. This study aimed to evaluate possible effects of the COVID-19 pandemic on the provision of ECPR in a regional-largest ECPR center.

All patients who received ECPR at Queen Mary Hospital between January 2019 and December 2020 were included. The characteristics of patients presenting in 2019 ("pre-COVID-19 period") were compared with those presenting in 2020 ("COVID-19 period"). Patient disease severity, characteristics of the ECMO run, and clinical outcomes in the pre-COVID-19 and COVID-19 periods were compared. The rates of in-patient admission for acute myocardial infarction and cardiac arrest were retrieved from a system-wide Clinical Data Analysis and Reporting System for comparison. The study was approved by The University of Hong Kong/Hospital Authority Hong Kong West Cluster Institutional Review Board (reference number UW 20-573). A two-sided $\mathrm{P}<0.05$ was considered statistically significant.

A total of 36 patients received ECPR-18 (50\%) in the pre-COVID-19 and 18 (50\%) in the COVID-19 period. By comparison, the number of admissions to the same hospital system for acute myocardial infarction was 393 in the preCOVID-19 and 370 in the COVID-19 period, and for cardiac arrest was 47 and 37, respectively. Amongst patients who received ECPR, the median age was 58 [49-62] years, and 24 (66.7\%) were male. Patients who received ECPR in the COVID-19 period had a lower mean Acute Physiology and Chronic Health Evaluation (APACHE) IV score (126 \pm 30 vs. $145 \pm 25 ; \mathrm{P}=0.047$ ) (Table 1). There was no significant difference in the median no-flow time $\{0[0-0]$ vs. $0[0-1]$ minutes; $\mathrm{P}=0.33\}$. The total low-flow time in the COVID-19 period was significantly shorter $\{43[35-52] v s$. 58 [41-74] minutes; $\mathrm{P}=0.044\}$, while the in-hospital lowflow time was similar $\{38$ [33-43] vs. 47 [40-63] minutes; $\mathrm{P}=0.064\}$. The total duration of ECMO support was longer in the COVID-19 period $\{100$ [48-156] vs. 39 [16-88] hours; $\mathrm{P}=0.014\}$. There was no significant difference in patient outcomes including hospital mortality (66.7\% vs. $83.3 \%$; $\mathrm{P}=0.25$ ), or intensive care unit (ICU) length of stay (LOS) $\{6$ [4-11] vs. 3 [1-10] days; $\mathrm{P}=0.100\}$.

The use of ECMO during the COVID-19 pandemic has been considered reasonable for traditional indications as well as for COVID-19 related cardiopulmonary failure $(3,4)$.

\footnotetext{
$\wedge$ ORCID: 0000-0001-6671-5963.
} 
Table 1 Characteristics of patients who received ECPR in the COVID-19 and pre-COVID-19 periods

\begin{tabular}{|c|c|c|c|}
\hline Characteristics & Pre-COVID-19 $(n=18)$ & COVID-19 $(n=18)$ & $P$ value \\
\hline Gender, $\mathrm{n}(\%)$, male & $11(61.1)$ & $13(72.2)$ & 0.72 \\
\hline \multicolumn{4}{|l|}{ Principal diagnosis, n (\%) } \\
\hline Cardiac arrest & $3(16.7)$ & $2(11.1)$ & 1.00 \\
\hline IHCA, n (\%) & $10(55.6)$ & $10(55.6)$ & 1.00 \\
\hline No-flow time ${ }^{a}$, median [IQR], minute & $0[0-1]$ & $0[0-0]$ & 0.33 \\
\hline Low-flow time ${ }^{\mathrm{b}}$, median $[\mathrm{IQR}]$, minute & $58[41-74]$ & 43 [35-52] & 0.044 \\
\hline Hospital low-flow time, median [IQR], minute & 47 [40-63] & 38 [33-43] & 0.064 \\
\hline SAVE score, median [IQR] & $1[-4$ to 3$]$ & $2[-7$ to 4$]$ & 0.82 \\
\hline ECMO duration, median [IQR], hour & 39 [16-88] & $100[48-156]$ & 0.014 \\
\hline ICU LOS, median [IQR], day & $3[1-10]$ & $6[4-11]$ & 0.10 \\
\hline ICU mortality, n (\%) & $14(77.8)$ & $11(61.1)$ & 0.28 \\
\hline Hospital mortality, n (\%) & $15(83.3)$ & $12(66.7)$ & 0.25 \\
\hline 3-month favorable $\mathrm{CPC}^{d}, \mathrm{n}(\%)$ & $3(16.7)$ & $4(22.2)$ & 0.67 \\
\hline
\end{tabular}

${ }^{a}$, no-flow time was defined as the time from the event of cardiac arrest to initiation of CPR by bystander or paramedic; ${ }^{b}$, low-flow time was defined as the time from initiation of CPR to either establishment of ECMO flow or sustained return of spontaneous circulation; ${ }^{\mathrm{c}}$, transfer time from ER to ICU only includes patients with OHCA. The number of patients with OHCA in pre-COVID-19 and COVID-19 group were 5 and $7 ;{ }^{d}$, favorable CPC included categories 1 (good cerebral performance) and 2 (moderate cerebral disability). ECPR, extracorporeal cardiopulmonary resuscitation; IHCA, in-hospital cardiac arrest; ER, emergency room; ICU, intensive care unit; APACHE, Acute Physiology and Chronic Health Evaluation; SAVE, survival after veno-arterial extracorporeal membrane oxygenation; ECMO, extracorporeal membrane oxygenation; LOS, length of stay; CPC, cerebral performance categories; CPR, cardiopulmonary resuscitation; OHCA, out-of-hospital cardiac arrest.

There are however particular concerns surrounding the use of ECPR, given the lack of well-established eligibility criteria, its resource-intensive characteristic, and the overall poorer patient outcomes. In a recent randomized clinical trial that was prematurely terminated due to evidence of benefit, there was a $36 \%$ absolute risk reduction in hospital mortality after ECPR compared with conventional resuscitation (2), making a case to offer such therapy to selected groups of patients in highly-specialized centers. We showed that continued provision of ECPR during the COVID-19 pandemic was possible in an established ECMO center, and patient mortality was similar to historically reported figures of $71 \%$ (5). Under the pandemic principles of allocating resources to a maximal number of patients who have the greatest chance of benefit, we observed that patients who were resuscitated with ECPR during the COVID-19 period had lower disease severity scores. Given the time-critical nature of initiating ECPR, there should be institutional guidelines for patient selection that are periodically reviewed depending on the pandemic situation and resource availability, and the ultimate decision be only left to experienced ECMO providers who are able to rapidly collate information to arrive at an adjudicated decision (6).

At the same time, it is notable that managing patients with lower disease severity scores may be associated with a paradoxically longer median duration of ECMO support and LOS in the ICU, because such patients typically have a lower mortality rate. The implications on healthcare costs, resource utilization, and ICU bed availability need to be considered before embarking on an ECPR program during 
the infectious disease outbreaks.

During ECPR for out-of-hospital cardiac arrest (OHCA), most patients are of unknown COVID-19 status, and the aim to achieve expeditious cannulation must be balanced against protecting healthcare workers from infection risks. We showed that the total and in-hospital low-flow time remained similar to pre-pandemic levels. It may be necessary for response teams to undergo highfidelity simulation training to adapt to a modification in the workflow such as requirements for donning personal protective equipment.

The limitations of the study include its retrospective nature and small sample size, precluding conclusions undermining the observed differences to be drawn. While anticipating data from larger registries, it should be considered reasonable to continue administering ECPR during the COVID-19 pandemic, but only at ECMO centers with experienced providers. The thresholds for initiation should be dynamic depending on the prevailing critical care resources.

\section{Acknowledgments}

Funding: This work was supported by an unrestricted philanthropic donation from Mr. and Mrs. Laurence Tse.

\section{Footnote}

Provenance and Peer Review: This article was a standard submission to the journal. The article has undergone external peer review.

Conflicts of Interest: All authors have completed the ICMJE uniform disclosure form (available at https://dx.doi. org/10.21037/jtd-21-1434). The authors have no conflicts of interest to declare.

Ethical Statement: The authors are accountable for all aspects of the work in ensuring that questions related to the accuracy or integrity of any part of the work are appropriately investigated and resolved.

Open Access Statement: This is an Open Access article distributed in accordance with the Creative Commons Attribution-NonCommercial-NoDerivs 4.0 International License (CC BY-NC-ND 4.0), which permits the noncommercial replication and distribution of the article with the strict proviso that no changes or edits are made and the original work is properly cited (including links to both the formal publication through the relevant DOI and the license). See: https://creativecommons.org/licenses/by-nc-nd/4.0/.

\section{References}

1. Emanuel EJ, Persad G, Upshur R, et al. Fair allocation of scarce medical resources in the time of Covid-19. N Engl J Med 2020;382:2049-55.

2. Yannopoulos D, Bartos J, Raveendran G, et al. Advanced reperfusion strategies for patients with out-of-hospital cardiac arrest and refractory ventricular fibrillation (ARREST): a phase 2, single centre, open-label, randomised controlled trial. Lancet 2020;396:1807-16.

3. Badulak J, Antonini MV, Stead CM, et al. Extracorporeal membrane oxygenation for COVID-19: updated 2021 guidelines from the extracorporeal life support organization. ASAIO J 2021;67:485-95.

4. Bartlett RH, Ogino MT, Brodie D, et al. Initial ELSO guidance document: ECMO for COVID-19 patients with severe cardiopulmonary failure. ASAIO J 2020;66:472-4.

5. Richardson AS, Schmidt M, Bailey M, et al. ECMO Cardio-Pulmonary Resuscitation (ECPR), trends in survival from an international multicentre cohort study over 12-years. Resuscitation 2017;112:34-40.

6. Worku E, Gill D, Brodie D, et al. Provision of ECPR during COVID-19: evidence, equity, and ethical dilemmas. Crit Care 2020;24:462.
Cite this article as: Ng PY, Fang S, Ip A, Ng AKY, Chan WM, Sin WC, Ngai CW. Changes in patterns of extracorporeal cardiopulmonary resuscitation during the COVID-19 pandemic. J Thorac Dis 2021;13(11):6499-6501. doi: 10.21037/jtd-21-1434 